\title{
CAPACITAÇÃO DO ENFERMEIRO AUDITOR NA GESTÃO EM SAÚDE: IMPORTÂNCIA E REALIDADE
}

\section{ENABLEMENT OF THE NURSE AUDITOR ON MANAGEMENT IN HEALTH: IMPORTANCE AND REALITY}

\section{CAPACITACIÓN DEL ENFERMERO AUDITOR EN LA GESTIÓN DE SALUD: IMPORTANCIA Y REALIDAD}

\section{Luciana Pertille da Costa}

Hospital Regina de Novo Hamburgo

lupertille@gmail.com

\author{
Paulo Fossatti \\ Centro Universitário La Salle de Canoas \\ irpaulo@unilasalle.edu.br
}

Submetido em: 19/03/2014

Artigo aceito em: 11/10/2014

\section{Resumo}

Este artigo é resultante de um estudo de caso. Destaca a importância da capacitação do enfermeiro auditor na gestão de instituição de saúde. Tem por objetivo sensibilizar os profissionais envolvidos na área da saúde quanto à importância da participação do Enfermeiro Auditor nos processos de gestão pertinentes aos espaços de saúde. A metodologia qualitativa analisa entrevistas com profissionais da administração hospitalar. O referencial teórico ancora-se em autores da atualidade sobre auditoria em instituição de saúde. Os resultados sinalizam três categorias: Importância do Enfermeiro auditor; conhecimento e utilização de ferramenta de gestão e capacitação técnica em auditoria.

Palavras-chave: gestão; capacitação em auditoria de enfermagem; instituição de saúde.

\begin{abstract}
This article is the result of a case study. It stresses the importance of the empowerment of the nurse auditor in the management of a health care institution. It aims to sensitize the health professionals about the importance of the participation of the Nurse Auditor in the processes of management pertinent to health spaces. The qualitative methodology analyzes interviews with hospital administration professionals. The theoretical reference anchors in today's authors about auditing in health institution. The results indicate three categories: importance of the Nurse Auditor; knowledge and use of a management tool and technical training in auditing.
\end{abstract}

Keywords: management; training in nursing audit; health institution.

\section{Resumen}

Este artículo proviene de un estudio de caso. Destaca la importancia de la capacitación del enfermero auditor en la gestión de institución de salud. Tiene por objetivo sensibilizar los profesionales involucrados en el área de la salud sobre la importancia de la participación del Enfermero Auditor en los procesos de gestión pertinentes a los espacios de salud. La metodología cualitativa analiza entrevistas con profesionales de administración hospitalario. El referencial teórico anclase en autores de la actualidad sobre la auditoria en instituciones de 

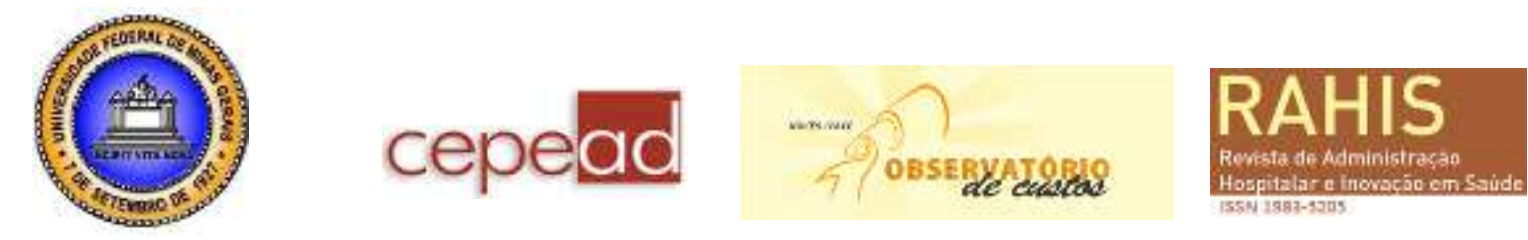

salud. Los resultados señalan tres categorías: Importancia del Enfermero Auditor; conocimiento y utilización de herramientas de gestión y capacitación técnica en auditoria. Palabras-clave: gestión; capacitación en auditorias de enfermería; institución de salud.

\section{INTRODUÇÃO}

A cada dia observamos a crescente participação de equipes multidisciplinares para auditoria na gestão de instituição de saúde. Com o passar do tempo e a experiência adquirida na prática profissional da enfermagem pode-se perceber o quanto o dia a dia da profissão influencia diretamente a vida das pessoas e a vida das organizações.

De acordo com Folland, Goodman e Stano (2008), a saúde e a assistência à saúde dominam o cenário econômico e político de vários países. Nos últimos 40 anos observou-se um rápido aumento nos gastos com assistência à saúde. Assim, tornou-se uma área especializada da economia demonstrar a magnitude e a importância do setor de saúde. $\mathrm{O}$ autor ressalta ainda a importância de reconhecermos as características peculiares dos mercados de assistência à saúde, para que possamos fazer a gestão em saúde com ferramentas apropriadas.

De acordo com Camelo et al. (2009), no atual cenário político-financeiro do país, o setor de saúde passou a procurar novas alternativas para a gestão, com foco na necessidade das organizações de saúde adaptarem-se a um mercado cada vez mais competitivo. A necessidade de garantir resultados positivos e clientes satisfeitos requer que as organizações aprendam a associar baixos custos com excelência de qualidade para seus clientes.

Na gestão em saúde, fazemos o recorte pelo serviço auditoria que visa à diminuição de perdas financeiras. O tema escolhido um estudo de caso sobre a importância do enfermeiro auditor na gestão de instituição de saúde percorre os processos de faturamento de instituições de saúde, através da utilização do conhecimento da auditoria no campo da enfermagem, viabilizando assim as cobranças, através da qualificação de todos os profissionais envolvidos na empresa.

E uma forma de qualificar estes profissionais dá-se através da educação continuada e de atualizações frequentes de procedimentos e recursos tecnológicos. Assim percebe-se a relevância em realizar estudo neste tema, visando à importância do enfermeiro auditor em validar o faturamento de informações e ações que precisam agilizar, facilitar e normalizar os processos de cobranças. Com eficiência, equidade, aceitabilidade e adequabilidade, o profissional da enfermagem, como auditor, encontra-se em posição privilegiada para atuar neste contexto em que a enfermagem permanece 24 horas em assistência ao cliente.

O termo auditoria tem sua origem no latim "audire”, que significa ouvir. Um auditor também é responsável pela veracidade e legitimidade dos fatos econômico-financeiros ao realizar relatórios a um superior referentes à participação de produção e lucros gerados. Porém, a auditoria não deve perder o foco na qualidade de assistência, dizem Camelo et al. (2009).

Neste cenário, o presente artigo tem como objetivo sensibilizar os profissionais envolvidos na área da saúde quanto à importância da participação do Enfermeiro Auditor nos processos de gestão pertinentes aos espaços de saúde. Com a intenção de atingir tal objetivo, buscamos alguns questionamentos que auxiliassem na condução desta pesquisa, bem como norteassem o desenvolvimento desse artigo, tais como: Existem ferramentas que possam auxiliar os processos de organização de custos e faturamento hospitalar? Há relação entre a ação de enfermagem, os custos do processo e a possibilidade de manutenção do serviço? Como se dá a formação do gestor em saúde para a auditoria? 

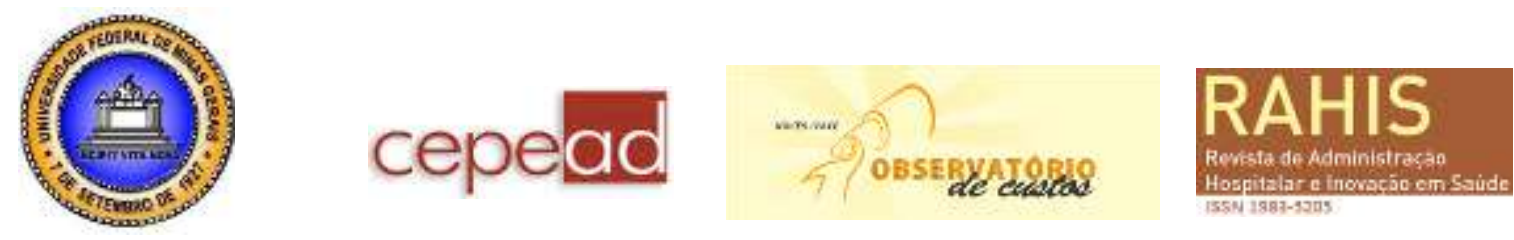

A partir destes questionamentos aplicamos entrevista semiestruturada com gestores em saúde. Para a análise dos dados utilizamos o aporte teórico em Folland, Goodman e Stano (2008), Alves (2009), Macedo e Macedo (2005) e André (2010). Também nos apoiamos em artigos científicos nas bases eletrônicas Scientific Electronic Library online (SciELO), Google Acadêmico e Capes periódicos. Os resultados da pesquisa sinalizam três categorias: importância do enfermeiro auditor; conhecimento e utilização de ferramenta de gestão e capacitação técnica em auditoria.

\section{METODOLOGIA}

A abordagem metodológica é de caráter qualitativo que se ocupa da compreensão de processos e fenômenos em um determinado campo de atuação profissional. Foi realizada análise documental com base em relatórios de pesquisa, prontuários, tabelas estatísticas e outros. Trata-se de documentos não convencionais, porém usuais no ambiente hospitalar, vinculando-se a relatórios de glosas de convênios de saúde e contas hospitalares já auditadas internamente no referido hospital.

Conforme Thomas e Nelson (1996), as pesquisas qualitativas envolvem a observação intensiva e de longo tempo num ambiente natural, com registro preciso e detalhado do que acontece no ambiente, seguido de interpretação e análise de dados, utilizando descrições e narrativas. Esta pesquisa é de caráter descritivo e procura-se analisar a frequência da ocorrência de um fenômeno, sua relação e conexão com outros, sua natureza e características, sem manipulá-lo.

Para a escolha dos entrevistados levou-se em consideração o grau de envolvimento destes no processo de faturamento, o tempo de experiência e o propósito do seu trabalho relacionado com a auditoria e a qualidade da assistência. . Os nomes foram preservados. Fazse referência aos mesmos usando-se os números 1,2 e 3 . A entrevistada $\mathrm{n}^{\circ} 1$ é gestora do setor de faturamento de uma instituição de saúde; possui dois anos de experiência nesse nosocômio. $\mathrm{O}$ entrevistado $\mathrm{n}^{\mathrm{o}} 2$ é supervisor assistencial de uma instituição de saúde; possui 10 anos de experiência na área de enfermagem. O entrevistado $\mathrm{n}^{\circ} 3$ é administrador de uma instituição de saúde; possui dois anos de experiência nesse nosocômio.

Primeiramente, esses profissionais foram convidados por contato telefônico, sendo perguntados se aceitariam participar da entrevista. Posteriormente à aceitação, foi enviado $e$ mail com o termo de consentimento livre e responsável e as informações para agendamento da entrevista.

A entrevista, previamente agendada, deu-se com questões semiestruturadas considerando três eixos de discussão, a saber: A importância da ação do Enfermeiro Auditor para que a Instituição se mantenha economicamente viável; O conhecimento de ferramenta de gestão que auxilia no processo de organização da gestão, custos e faturamento hospitalar e por último a importância da capacitação dos profissionais envolvidos.

\section{REFERENCIAL TEÓRICO}

Para sustentar este estudo buscamos referenciais teóricos em autores de renome nacional e em bases eletrônicas como Scientific Electronic Library online (SciELO), Google Acadêmico e Capes periódicos os quais fornecem o aporte necessário para o desenvolvimento e análise da pesquisa. 

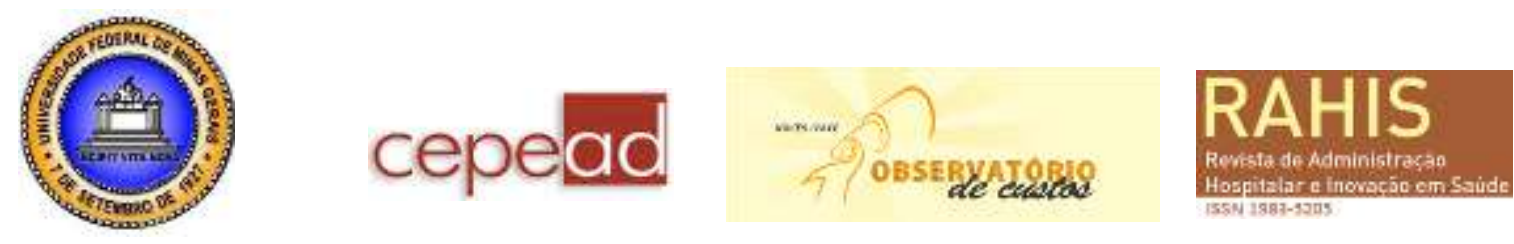

A revisão da literatura permite observar que as dimensões conceituais de métodos, de finalidade e legislação de auditoria em enfermagem, permanecem com lacunas de compreensão, requerendo novas investigações (SCARPARO, FERRAZ, 2008).

De acordo com Ferreira e Braga (2009), auditoria significa a realização de operações financeiras ou registros de transações financeiras, visando determinar sua correção ou legalidade. A auditoria consiste em uma técnica contábil do sistemático exame dos registros que visa apresentar conclusões, críticas e opiniões sobre as situações patrimoniais e aquelas dos resultados, quer formados, quer em processo de formação. Isto amplia a compreensão da ação do auditor para além da mera verificação dos fatos, introduzindo a noção do encaminhamento crítico dos resultados apurados (PINTO e MELO, 2010). A afirmação descrita nos leva a repensar como a auditoria será implementada e como ela é vista pelos colaboradores, sua forma de direcionamento, ações e sua execução.

Para Scarparo e Ferraz (2008), no exercício da auditoria faz-se necessária a construção de instrumentos que devam contemplar os objetivos de acordo com a estrutura, processo e resultado da assistência, definindo o caminho a percorrer para o alcance da qualidade.

Assim, segundo Costa (2001), considera-se auditoria, no âmbito deste artigo, a análise crítica e sistemática da eficiência, economicidade e qualidade da assistência prestada aos usuários dos serviços de saúde. Esta conceitualização surgiu nos Estados Unidos, no início da década de 60, como consequência da crise da qualidade no ensino em saúde e das instituições de saúde daquele país.

No Brasil, a auditoria é mais recente; somente na década de 60, quando a assistência médica brasileira passou por profundas alterações, com a extinção e a fusão das caixas de Previdência e Assistência Médica e a criação do Instituto Nacional de Previdência Social (INPS). Nesta nova estrutura ficou clara a necessidade do desenvolvimento de um novo sistema para corrigir falhas e elevar os padrões técnicos, administrativos e éticos dos profissionais ligados às áreas da saúde, com a finalidade de melhorar o atendimento à população.

Para Ferreira e Braga (2009), a prática da auditoria recebeu novas diretrizes na busca de atender as necessidades das grandes empresas, surgindo na área da saúde, sendo realizada pela primeira vez em trabalho realizado pelo médico George Gray, nos Estados Unidos, no ano de 1918. Em seu trabalho foi verificada a qualidade da assistência prestada ao cliente através dos registros no prontuário médico.

Cabe ressaltar que antes de 1976, as atividades de auditoria no Brasil eram realizadas pelos supervisores conforme INPS, por meio de apuração em prontuários de clientes e contas hospitalares, porque nesta época não havia auditoria direta em hospitais.

No ano de 1983 é reconhecido o cargo de médico auditor e a auditoria passa a ser feita nos próprios hospitais brasileiros. E, neste mesmo ano, acontece no Brasil o início de experiências isoladas com auditoria médica, visando ao fornecimento de informações para decisões administrativas e para o corpo clínico, realizada no Hospital de Ipanema, no Rio de Janeiro. Já Ferreira e Braga (2009) afirmam que a auditoria na área da enfermagem surgiu no Hospital Universitário de São Paulo, através de um processo implantado desde 1983, com padrões estabelecidos para sustentar a Sistematização da Assistência de Enfermagem (SAE). Com o mesmo objetivo, outros hospitais universitários no Brasil implantaram na década de 80 este método avaliativo.

Com base nestes autores, percebemos que existem formas e ferramentas com as quais se pode conciliar a assistência à saúde de qualidade juntamente com o faturamento. Macedo e Macedo (2005), por exemplo, afirmam que o Serviço de Análise e Auditoria Interna 

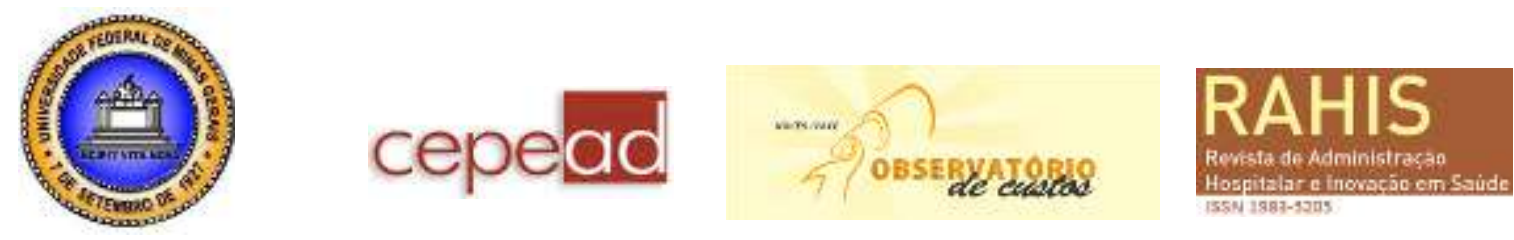

(S.A.A.I.) constitui um veículo de comunicação de apoio ao Conselho de Administração, sendo independente de qualquer outro serviço do hospital.

O objetivo do S.A.A.I. é contribuir para assegurar a melhor utilização dos recursos disponíveis, dar proteção aos meios postos à disposição dos funcionários e usuários, e dar prosseguimento à intenção do hospital a alcançar maiores níveis de eficiência e eficácia possíveis. E cabe ao S.A.A.I. a realização de dois grandes grupos de tarefas: a elaboração de análises periódicas e realização de auditorias; e a elaboração do relatório mensal dos documentos analisados, que também representa peça essencial no acompanhamento das atividades do hospital e dos seus serviços.

Os relatórios contêm análises dos Serviços, áreas e atividades auditadas, identificam as falhas encontradas e sugerem os melhoramentos necessários no entender do S.A.A.I. O conjunto proporciona, dessa forma, uma leitura da realidade do hospital e apresenta soluções que devem ser equacionadas no quadro do planejamento da atividade para o exercício. Mesmo depois de viabilizadas as medidas propostas, continua a ser de interesse a consulta aos relatórios, para compreender a evolução do hospital, formar melhor seus profissionais e mencionar na programação as atividades de auditoria futuras.

Ainda de acordo com os autores mencionados, a realização das ações de auditoria, o S.A.A.I., visa fundamentalmente à proteção do patrimônio do hospital; a veracidade e integridade da informação produzida; a observância dos procedimentos legais, do regulamento interno e das normas técnicas instituídas; a utilização econômica dos recursos e a identificação dos pontos fortes e fracos encontrados, segundo uma perspectiva pedagógica e corretiva.

Neste sentido, os autores destacam que:

As áreas operacionais do hospital são as responsáveis pelo movimento da maioria dos meios materiais e humanos ao serviço do mesmo. Desta forma, os resultados globais são largamente determinados pela correção das decisões tomadas a este nível e pelo cumprimento das normas estabelecidas. Para este efeito, compete ao S.A.A.I., no âmbito das ações de inspeção ordenadas pelo Conselho administrativo (MACEDO e MACEDO, 2005, p.65).

Deste modo, percebemos que todo o processo de auditoria deve ser acompanhado de competência técnica e profissional. Requer um agir com zelo e responsabilidade, trabalhar com independência e comportar-se com ética, guardar sigilo durante a execução e divulgação dos trabalhos realizados. Tem como objetivo melhorar os resultados através de uma revisão sistemática dos cuidados e, diferentemente da meta-análise, objetivam análises específicas para cada serviço e podem indicar alterações a serem implantadas em todos os níveis (individual, em equipes ou total do serviço).

Podemos realizar de diferentes formas, conforme apresentadas por André (2010), auditoria baseada em protocolos e diretrizes; baseadas na procura de ocorrências adversas ou incidentes críticos ou auditoria de assuntos específicos.

Com as diferentes formas de auditoria percebemos que depende da diretriz da instituição o modelo a ser instituído na mesma. A partir das diversas formas apresentadas por André (2010), fica claro que, para se desenvolver uma auditoria com as ferramentas escolhidas pela instituição a equipe de profissionais precisa estar unida nas diretrizes da empresa. 

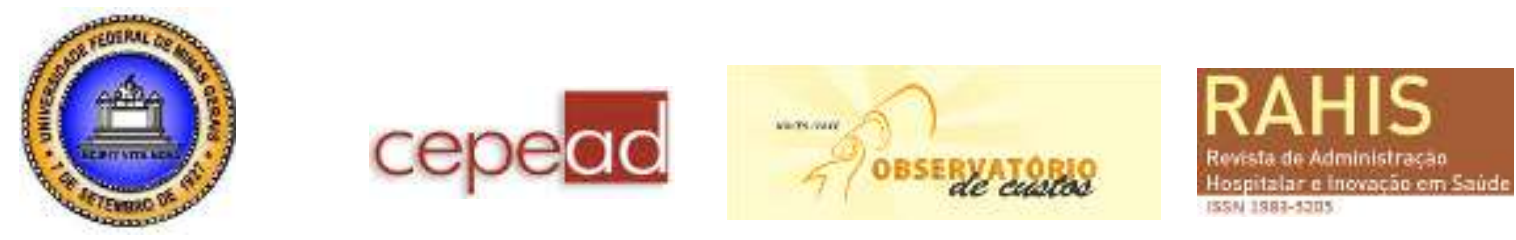

Nesse contexto, entende-se que a auditoria em enfermagem cumpre uma finalidade institucional que, na atualidade, está pautada em um enfoque empresarial e mercadológico. Há, contudo, uma tendência de mudança do enfoque de mercado voltado para o cliente, portanto, pautado na qualidade do produto ou serviço, havendo a adequação das ações da auditoria em enfermagem nesse sentido (SCARPARO e FERRAZ, 2008).

Considerando-se que todos os processos necessitam passar por avaliações em busca de qualidade nos serviços e nos mais variados setores que compreendem as instituições de saúde, entende-se que a acreditação está fundamentada em princípios éticos claramente estabelecidos e que utiliza ferramentas metodológicas reconhecidamente eficazes no campo da avaliação, o que confere alta credibilidade ao processo, conforme Alves (2009).

Os padrões internacionais e o método de avaliação de acreditação são desenhados para munir-se de informações e estabelecer indicadores em saúde, voltados para a qualidade do cuidado ao paciente, que possibilitam melhorias efetivas no desenvolvimento das atividades clínicas e gerenciais. $\mathrm{O}$ compromisso com a qualidade é um incentivo à mudança de atitudes e de comportamento, bem como incentiva o trabalho coletivo, principalmente o de grupos multidisciplinares, no aperfeiçoamento dos processos de atendimento.

Em vista disto, os benefícios para as instituições que adotam o modelo de compromisso com a qualidade são os seguintes: ter um modelo de gestão para a qualidade, "Benchmarking" com alguns hospitais de referência; reuniões periódicas de orientação e troca de experiência; participação de eventos sobre qualidade; assessoria específica sobre controle de infecção hospitalar; pesquisa com usuários; visitas periódicas de avaliação por equipe técnica; reconhecimento da conformidade (selo) e Prêmio Nacional da Gestão em Saúde (PNGS).

O trabalho em equipe é fundamental para o sucesso dos objetivos e o comprometimento dos profissionais envolvidos. De acordo com Teisberg e Porter (2007), a qualidade inferior não gera economias na assistência à saúde, tampouco na maioria dos outros setores. Pelo contrário, baixa qualidade leva a complicações e à necessidade de tratamentos adicionais, que elevam substancialmente o custo. Por isso, é tão importante a harmonia da equipe e os processos de habilidades instalados na instituição visando sempre a melhor resolução das inconformidades.

Ferreira e Braga (2009) afirmam ser indiscutível a necessidade e a importância de um sistema de informação que propicie a todos os elementos da equipe de enfermagem, informações necessárias ao desenvolvimento da assistência. Assim sendo, o sistema de informação em enfermagem viabiliza o processo de comunicação entre os integrantes da equipe de saúde e o cliente.

Existe atualmente uma série de organizações que praticam a avaliação da qualidade da saúde em instituições de forma global, como, por exemplo, a Organização Internacional para Padronizações (ISSO) e a Organização Nacional de Acreditação (ONA), além de comissões internas que possibilitam a execução da avaliação, sendo esta a comissão da auditoria em enfermagem, responsável por atuar em vários hospitais. Desta forma, percebe-se que no Brasil a auditoria vem tomando impulso nos últimos cinquenta anos, necessitando ainda de alguns arranjos que melhor se adaptem ao processo da realidade brasileira.

Kurcgant (2005) sugere que a necessidade de os serviços de saúde aprimorar os sistemas de gerenciamento desses recursos, a fim de garantirem uma assistência contínua de qualidade a um menor custo e a quantidade e qualidade dos materiais necessários para que os profissionais realizem suas atividades sem riscos para si mesmos e para os pacientes. Assim, precisamos atentar para o aumento na qualidade dos tratamentos que contribuam para 

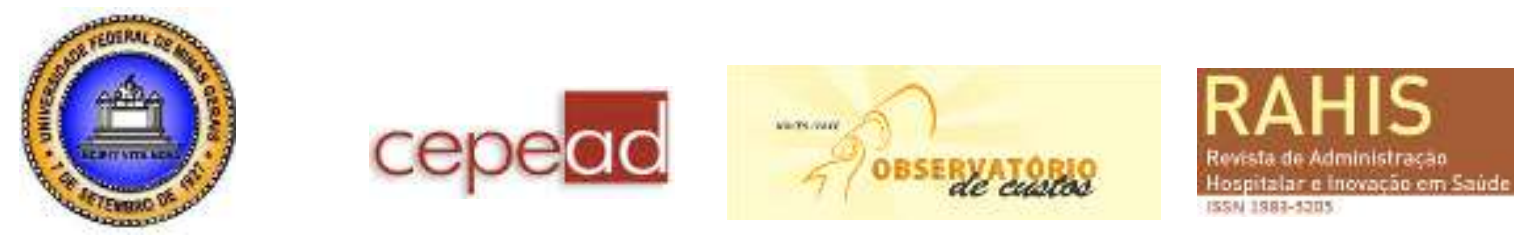

aumentos nos gastos. Nessa linha, a inter-relação entre seguro, tecnologia e consumo é de grande interesse para os gestores institucionais.

O processo de melhorias na produtividade aumenta a produção. Alternativamente, o mesmo produto pode ser produzido com menos insumos. Num sentido macroeconômico, melhorias gerais na produtividade representam uma principal fonte de crescimento econômico e de ascensão dos padrões de vida. Num nível microeconômico, os ganhos em produtividade numa instituição podem levar a menores preços para os bens e serviços produzidos naquele local e possivelmente a maiores taxas de remuneração aos trabalhadores, afirmam Folland, Goodman e Stano (2008).

Durante o processo de educação continuada que visa o aprimoramento e aperfeiçoamento dos profissionais de saúde da instituição hospitalar surgiu a necessidade de sensibilizar os membros das equipes quanto à importância dos registros de enfermagem e do envolvimento no processo de trabalho, podendo se utilizar de ferramentas educativas para tal, sempre enfatizando que esta servirá como respaldo legal sobre a qualidade da assistência prestada ao cliente e quanto aos valores que a instituição receberá ou não dependendo desse registro (FERREIRA e BRAGA, 2009).

Ampliando nossa busca pelo referencial teórico em bases eletrônicas como Scientific Electronic Library online (SciELO), Google Acadêmico e Capes periódicos, ainda encontramos alguns autores problematizando a questão em tela, como registramos a seguir.

Para Scarparo e Ferraz (2008) a finalidade da auditoria em enfermagem está restrita à comprovação de pagamento de contas hospitalares, revendo glosas por meio de relatório técnico e realizando negociações entre representantes do hospital e do convênio; no futuro, associado à primeira finalidade a intenção será apontar inadequações da saúde, reformulando suas práticas, indicando processos de educação em serviço e delineando ações corretivas. Com relação às prioridades a serem implementadas para a prática futura foram pontuados a formação específica (especialização) e o planejamento e execução da assistência de forma sistemática, pautada no conhecimento científico e técnico da profissão.

Com o foco na assistência de qualidade e no aumento da competitividade entre organizações que prestam serviços de saúde, Pinto e Melo (2010) afirmam que cada vez mais surgem oportunidades para o profissional enfermeiro atuar na área de auditoria de contas hospitalares. A auditoria configura-se como uma ferramenta gerencial utilizada pelos profissionais da saúde, em especial os enfermeiros, com a finalidade de avaliar a qualidade da assistência de enfermagem e os custos decorrentes da prestação dessa atividade.

Para Pinto e Melo (2010) a significativa presença da enfermagem entre os profissionais que atuam nos serviços de auditoria em saúde denota a relação que existe entre as responsabilidades assumidas por enfermeiras na prática assistencial e o conhecimento necessário para o trabalho no campo da auditoria. Isto porque o profissional que atua na maior parte dos procedimentos relacionados à assistência prestada ao usuário, desde o atendimento direto, até as atividades administrativas e gerenciais é o enfermeiro, o que lhe confere alguma competência técnico-administrativa para lidar com o processo de produção de conta hospitalar. A auditoria se entendida como um processo educativo fornece subsídios para a implantação e gerenciamento de uma assistência de qualidade.

Entende-se que a prática do enfermeiro auditor pode se constituir em uma intervenção de relevância, que vá além da função de servir apenas aos interesses das organizações onde atuam. Estando inserido em uma política de saúde e num contexto de organizações de saúde cuja finalidade explicite o que se espera desta prática, tal como a contribuição para a qualidade da assistência de enfermagem e a atenção à saúde da população de um modo geral. 

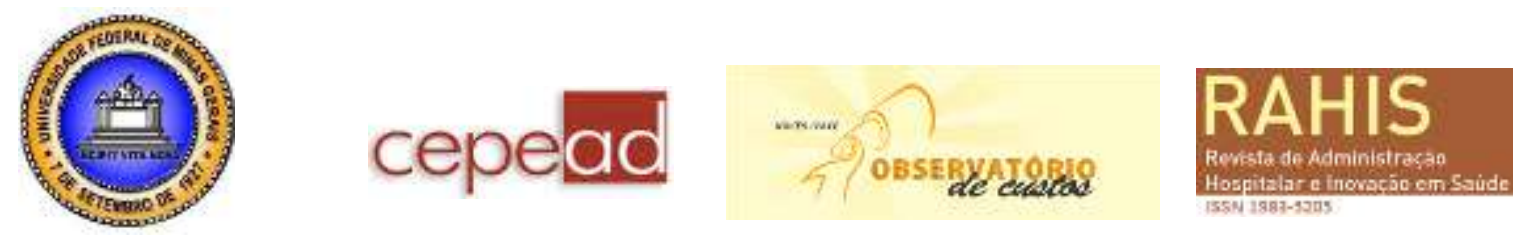

Para Paim e Ciconelli (2007) a qualidade deixou de ser um pré-requisito opcional, mas é um requisito obrigatório de sobrevivência em um mercado cada vez mais competitivo.

\section{ANÁLISE E DISCUSSÃO DOS RESULTADOS}

O resultado da pesquisa centra-se em três categorias como já anunciado anteriormente: importância do enfermeiro auditor; conhecimento e utilização de ferramenta de gestão e capacitação técnica em auditoria.

\section{Importância do Enfermeiro Auditor}

Esta categoria analisa a percepção dos entrevistados sobre a importância do Enfermeiro Auditor para que a instituição hospitalar se mantenha economicamente viável.

As respostas dos entrevistados apontam para uma unanimidade. Todos consideram importante a ação do enfermeiro auditor para que a instituição da saúde se mantenha economicamente viável. Salientam que o acompanhamento seja semanal ou mensal, pois os resultados, quando analisados e avaliados, contribuem para a melhoria do atendimento e qualidade dos serviços prestados, a exemplo do que diz o entrevistado $\mathrm{n}^{\circ} 3$ :

\footnotetext{
O papel do enfermeiro auditor é de fundamental importância considerando o melhor aproveitamento da produção realizada pelas áreas médico-assistenciais, visto o reconhecido problema dos registros de procedimentos realizados e consumos de cada paciente que muitas vezes não são debitados adequadamente.
}

A confirmação da importância do enfermeiro auditor por nossos entrevistados condiz com o que afirmam os autores Ferreira e Braga (2009), Pinto e Melo (2010), Camelo, et al (2009), Scarparo e Ferraz (2008). É unânime a opinião destes autores ao dizerem que o enfermeiro auditor necessita de métodos e parâmetros legais que sustentam na prática a auditoria de enfermagem. Para Pinto e Melo (2010), o enfermeiro pode atuar sugerindo mudanças de rotinas organizacionais e subsidiar a educação continuada com o enfoque na prestação de serviços de qualidade.

Compreendemos que, nos dias de hoje, para realizar a auditoria de enfermagem é necessário que se reconheçam as transformações, no plano econômico, político e tecnológico pelas quais vêm passando as organizações de um modo geral, o que não é tarefa fácil. A aplicação do método de auditoria deve estar de acordo com os objetivos e metas organizacionais.

De acordo com Pinto e Melo (2010), a significativa presença do enfermeiro auditor entre os profissionais que atuam nos serviços de auditoria em saúde denota a relação que existe entre as responsabilidades assumidas por enfermeiros na prática assistencial e o conhecimento necessário para o trabalho no campo da auditoria. Isso porque o profissional que atua na maior parte dos procedimentos relacionados à assistência prestada ao usuário, desde o atendimento direto, até as atividades administrativas e gerenciais, é o enfermeiro o que lhe confere competência técnica-administrativa para lidar com o processo de produção da conta hospitalar.

Atualmente os enfermeiros estão se especializando como auditores, pois as instituições estão à procura de profissionais altamente qualificados nesta área. Consideramos relevante para as instituições em ascensão no mercado a presença do enfermeiro auditor. A estes é 

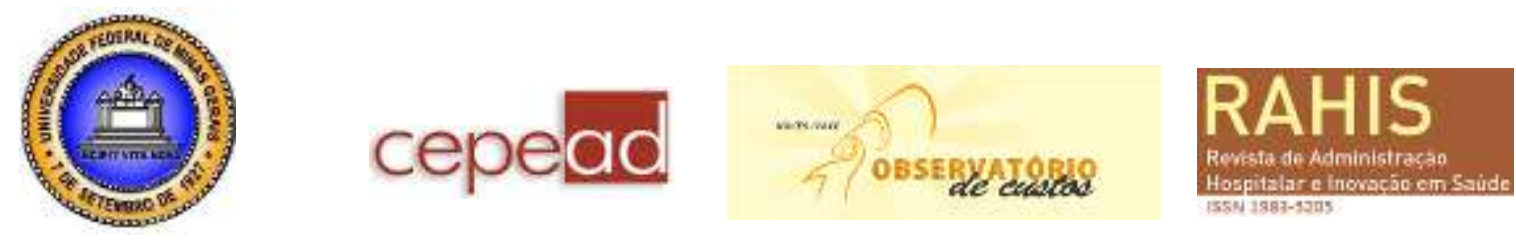

exigido o comprometimento com o desenvolvimento de pessoas como forma de fortalecer os objetivos organizacionais.

\section{Conhecimento e utilização de ferramenta de gestão}

Neste sentido, conforme André (2010), o processo de auditoria deve ser seguido de competência técnica e profissional, agir com zelo e responsabilidade, trabalhar com independência e comportar-se com ética, guardar sigilo durante a execução e divulgação dos trabalhos realizados. Tem-se assim, como principal resultado, as análises específicas para cada serviço, indicando alterações a serem implantadas em todos os níveis (individual, em equipes ou em todo o serviço).

De acordo com as respostas dos entrevistados os profissionais da enfermagem conhecem alguma ferramenta para o auxílio do processo de organização da gestão bem como percebem a importância da utilização da mesma para o processo de gestão. Para tal, salientam que a formação e a experiência do profissional são fundamentais para o processo de auditoria, organização e gestão. O entrevistado $\mathrm{n}^{\circ} 2$ cita: "Sim, o Advance Strategic (SA), ritmo, acompanhamento semanal, dos custos, faturamento e produção". O entrevistado cita o modelo de ferramenta de gestão utilizada pela instituição onde trabalha o que comprova seu envolvimento com as ferramentas de gestão. A partir desta relação de dados o profissional irá fazer as conclusões junto à sua equipe e elaborar um plano estratégico para o desenvolvimento da organização envolvida.

Neste sentido, Scarparo e Ferraz (2008) colaboram com a presente análise dizendo que para a realização da auditoria é importante a construção de instrumentos que devam contemplar os objetivos de acordo com a estrutura, processo e resultado da assistência, definindo o caminho a percorrer para o alcance da qualidade.

Para Dias (2011), a temática da ferramenta é uma tendência para o gerenciamento dos serviços de enfermagem a ser utilizada nos processos de tomada de decisão dos enfermeiros. $\mathrm{O}$ serviço de auditoria de enfermagem necessita realizar um trabalho proativo visando à redução dos desperdícios com medicamentos e materiais. Para tal, é importante a revisão das rotinas e implantação de programas de treinamento para a conscientização da equipe de enfermagem quanto à importância dos recursos financeiros do hospital. Ações de educação continuada tornam-se necessárias para a garantia qualificada do gerenciamento destes serviços.

O conhecimento de ferramentas poderá contribuir para a otimização dos recursos físicos e matérias disponíveis nos serviços de saúde. O bom conhecimento e o uso de ferramentas de gestão ajudam a desenvolver pessoas, melhorando, além do planejamento e a execução técnica do trabalho a relação custo - benefício para o paciente, o hospital e o comprador do serviço de saúde. Este posicionamento vem ao encontro de Pinto e Melo (2010, p. 672), ao afirmarem: "a auditoria pode ser entendida como um processo educativo e fornece subsídios para a implantação e gerenciamento de uma assistência de qualidade".

\section{Capacitação técnica em auditoria}

As evidências presentes nas respostas dos entrevistados apontam para uma determinada unanimidade, pois todos concordam e acreditam que a capacitação aprofundada dos profissionais envolvidos na auditoria é fundamental para diminuir perdas financeiras e manter a qualidade da assistência aos pacientes. O entrevistado $\mathrm{n}^{\circ} 1$ afirma: 
Sim, estes profissionais têm por objetivo principal a qualidade da assistência ao paciente, mas a capacitação do enfermeiro em auditoria é de profunda importância, pois têm como foco diminuir as perdas financeiras, além de ter amplo conhecimento técnico que auxilia diretamente as áreas de apoio como o faturamento por exemplo.

Para a entrevistada, a qualidade da assistência é importante e, portanto, deve ser prioridade, estabelecendo relação entre o trabalho e os registros, os custos. Esta relação é fundamental e só é possível se houver a implantação das ferramentas anteriormente citadas, além de mencionar a capacitação do enfermeiro e a necessidade de uma boa assistência ao paciente.

Para Ferreira e Braga (2009), é indiscutível a importância de um sistema de informação que propicie a todos os elementos da equipe de enfermagem as informações necessárias ao desenvolvimento da assistência, visando o processo de comunicação entre os integrantes da equipe de saúde e o paciente.

Acreditamos que, além de termos profissionais qualificados tanto na assistência quanto no setor de faturamento, poderemos contar com funcionários envolvidos no processo, pois buscamos atualmente a auditoria de qualidade da assistência com redução de custos, agregando os valores financeiros aos valores qualitativos. Melhorar a assistência deve ser o foco de atenção da equipe para que possa estar em consonância com as expectativas do cliente. Consoante Camelo, et al. (2009, p. 1022):

A auditoria vem tomando novas dimensões mostrando sua importância dentro das instituições hospitalares [...], proporcionando através de seus resultados benefícios que atingem a equipe de enfermagem que revendo as atividades desempenhadas e os resultados que se deseja alcançar obtém subsídios que estimulam a reflexão profissional, possibilitando uma enfermagem científica.

Os profissionais na atualidade são convidados a envolver-se com os processos de melhorias e qualificações. Da mesma forma o estímulo ao aprendizado tende a ser focado nos processos de gestão. De acordo com a conclusão de Paim e Ciconelli (2007, p. 91):

\begin{abstract}
Assim, o desenvolvimento de sistemas de qualificação deve ser entendido como um primeiro passo das organizações no sentido de alcançarem maior eficiência e eficácia dos seus processos, visando à melhoria e a satisfação dos seus clientes. O sucesso de qualquer organização depende diretamente da sua capacidade em mobilizar e organizar os meios e os recursos necessários que satisfaçam as exigências, em um processo mútuo de crescimento, resultando em qualidade e otimização dos serviços proporcionados pelos prestadores.
\end{abstract}

Desta forma, existe a necessidade premente de intenso investimento em educação permanente ou auditoria educativa, visando à promoção do conhecimento e a sensibilização da equipe multidisciplinar.

O caminho a ser percorrido para a implantação de Enfermeiro Auditor e sua capacitação é longo, pois é uma especialidade que vai sendo adquirida com a necessidade do mercado de trabalho. Este último se tornou atrativo para esses profissionais que têm o conhecimento técnico-científico e viram a oportunidade de desempenhar sua profissão de outra forma além da enfermagem propriamente dita. 

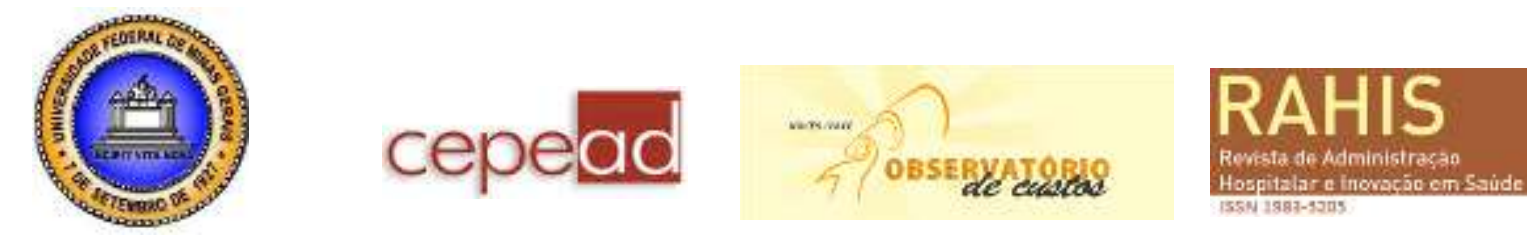

\section{CONSIDERAÇÕES FINAIS}

O objetivo principal deste estudo é sensibilizar os profissionais envolvidos na área da saúde quanto à participação do Enfermeiro Auditor nos processos de gestão pertinentes aos espaços de saúde. Este profissional pode se utilizar de ferramentas de gestão visando a qualidade da assistência prestada ao cliente.

Os resultados da pesquisa apontam para a importância da auditoria de enfermagem na avaliação da qualidade dos serviços de saúde dentro do processo de gestão da Instituição. A finalidade da auditoria de enfermagem, na atualidade, está restrita à comprovação de pagamento de contas hospitalares, revendo glosas por meio de relatório técnico e realizando negociações entre representantes do hospital e do convênio. Há uma tendência de mudança de enfoque de mercado voltado para o cliente. Portanto, pautado na qualidade do serviço podem correr adequações das ações da auditoria em enfermagem.

Da mesma forma, o conhecimento e o uso das ferramentas de gestão para a auditoria em saúde, por parte do enfermeiro apresentou-se uma necessidade singular na atualidade. As pessoas são cada vez mais informadas e passam a ter amplo poder de crítica e escolhas. Tal realidade reforça a importância da formação eu auditoria em saúde no cumprimento de normas básicas de segurança, no atendimento em estabelecimento de saúde, dentre outros.

Acreditamos que este estudo não se finaliza aqui. A partir desta pesquisa novas possibilidades de estudos deverão surgir, a exemplo da importância do conhecimento em educação no âmbito da Saúde.

\section{REFERÊNCIAS}

ALVES, V. L. S. Gestão da Qualidade: ferramentas utilizadas no contexto contemporâneo da saúde. São Paulo: Martinari, 2009.

ANDRÉ, A. M. Gestão Estratégica de Clínicas e Hospitais. São Paulo: Atheneu, 2010.

CAMELO, S. H. H. et al. Auditoria de enfermagem e a qualidade da assistência à saúde: uma revisão da literatura. Revista Eletrônica de Enfermagem, v. 11, n. 4, p. 1018-1025, 2009. Disponível em: <http://www.fen.ufg.br/revista/v11/n4/pdf/v11n4a28.pdf>. Acesso em: 14 out. 2011.

COSTA, C. C. V. Manual de Auditoria Médico-Hospitalar. Curitiba: Paranaset, 2001.

DIAS, T. C. L. et al. Auditoria em enfermagem: revisão sistemática da literatura. Rev. bras. enferm. [online]. Brasília, v. 64, n. 5, p. 931-937, 2011. Disponível em <http://www.scielo.br/pdf/reben/v64n5/a20v64n5.pdf>. Acesso em: 19 mar. 2014.

FERREIRA, T. S.; BRAGA, A. L. S. Auditoria em Enfermagem: O Impacto das anotações de enfermagem no contexto das glosas Hospitalares. 2009. Disponível em: $<$ http://www.uff.br/anaissegerenf/premio/AUDITORIA\%20EM\%20ENFERMAGEM\%20O \%20IMPACTO $\% 20$ DAS $\% 20$ ANOTA $\%$ C7\%D5ES\%20DE\%20ENFERMAGEM $\% 20$ NO $\% 2$ 0CONTEXTO\%20DAS\%20GLOSAS\%20HOSPITALARES.pdf>. Acesso em: 20 out. 2011. 


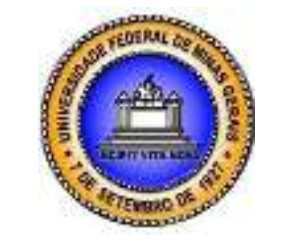

\section{cepeserc}

FOlland, S.; GOODMAn, A. C.; STANO, M. A Economia da Saúde. 5. ed. Porto Alegre: Bookman, 2008.

KURCGANT, P. Gerenciamento em Enfermagem. Rio de Janeiro: Guanabara, 2005.

MACEDO, N.; MACEDO, V. Gestão Hospitalar: Manual Prático. Lisboa: Lidel, 2005.

MARQUES, M. O. Escrever é Preciso: o princípio da pesquisa. 4. ed. Ijuí: Unijuí, 2001.

PAIM, C. R. P.; CICONELLI, R. M. Auditoria de Avaliação da qualidade dos serviços de saúde. Revista de Administração de Saúde, v. 9, n. 36, p. 85-91, 2007. Disponível em: <http://www.cqh.org.br/portal/pag/doc.php?p_ndoc=219> . Acesso em: 24 fev. 2014.

PINTO, K. A.; MELO, C. M. M. A prática da enfermeira em auditoria em saúde. Rev. esc. enferm. USP [online]. São Paulo, v. 44, n. 3, p. 671-678, 2010. Disponível em:<http://www.scielo.br/pdf/reeusp/v44n3/17.pdf>. Acesso em: 24 fev. 2014.

SCARPARO, A. F.; FERRAZ, C. A. Auditoria em Enfermagem: identificando sua concepção e métodos. Revista Brasileira de Enfermagem. Brasília, v. 61, n. 3, p. 302-305, maio/jun 2008. Disponível em: < http://www.scielo.br/pdf/reben/v61n3/a04v61n3.pdf>. Acesso em 20 out. 2011.

TEISBERG, E. O.; PORTER, M. E. Repensando a Saúde. Porto Alegre: Bookman, 2007.

THOMAS e NELSON. Tipos de Pesquisa considerando os Procedimentos Utilizados. 1996. Disponível em: <http://www.ergonomia.ufpr.br/Tipos\%20de\%20Pesquisa.pdf>. Acesso em: 18 mar. 2014. 